\title{
A Stable Carbon Nanotube Nanofluid for Latent Heat-Driven Volumetric Absorption Solar Heating Applications
}

\author{
Nathan Hordy, ${ }^{1}$ Delphine Rabilloud, ${ }^{2}$ Jean-Luc Meunier, ${ }^{1}$ and Sylvain Coulombe ${ }^{1}$ \\ ${ }^{1}$ Plasma Processing Laboratory, Department of Chemical Engineering, McGill University, 3610 University Street, \\ Montreal, QC, Canada H3A 0C5 \\ ${ }^{2}$ Ecole Centrale de Lyon, 36 Avenue Guy de Collongue, 69134 Écully, France \\ Correspondence should be addressed to Nathan Hordy; nathan.hordy@mail.mcgill.ca
}

Received 1 March 2015; Accepted 14 June 2015

Academic Editor: Paulo Cesar Morais

Copyright (C) 2015 Nathan Hordy et al. This is an open access article distributed under the Creative Commons Attribution License, which permits unrestricted use, distribution, and reproduction in any medium, provided the original work is properly cited.

\begin{abstract}
Recently, direct solar collection through the use of broadly absorbing nanoparticle suspensions (known as nanofluids) has been shown as a promising method to improve efficiencies in solar thermal devices. By utilizing a volatile base fluid, this concept could also be applied to the development of a direct absorption heat pipe for an evacuated tube solar collector. However, for this to happen or for any other light-induced vapor production applications, the nanofluid must remain stable over extended periods of time at high temperatures and throughout repetitive evaporation/condensation cycles. In this work, we report for the first time a nanofluid consisting of plasma-functionalized multiwalled carbon nanotubes (MWCNTs) suspended in denatured alcohol, which achieves this required stability. In addition, optical characterization of the nanofluid demonstrates that close to $100 \%$ of solar irradiation can be absorbed over a relatively small nanofluid thickness.
\end{abstract}

\section{Introduction}

As of 2012, solar water heating was second to wind energy in global capacity for new renewable energy sources [1]. Used primarily for domestic hot water generation, solar heating is expected to form a significant fraction of our global energy demand particularly in developing countries, where the use of natural gas and electricity to heat water is often not an option. With more than half of the cumulative capacity and $78 \%$ of newly installed capacity (2010), evacuated tube collectors (ETCs) represent the majority of the global market $[1,2]$. This capacity includes ETCs in which water is heated directly or indirectly through the use of a heat pipe. The latter, which is the focus of this work, consists essentially of a heat pipe surrounded by an evacuated glass tube [3]. As the solar irradiation heats the device, the volatile fluid contained within the heat pipe boils. The produced vapors rise and condense within a manifold at the top of the collector, transferring energy that directly or indirectly heats water. Direct solar vapor generation through the use of a highly absorbent nanofluid could improve the efficiency of the heat pipe as volumetric collection reduces surface energy losses [4]. As well, some researchers have reported that as nanoparticles are locally absorbing vapors may be produced much quicker than traditional boiling as the entire bulk fluid does not have to be heated [5]. To date, only a handful of studies have examined the possibility of large scale vapor production using optical absorption [5-8], although many studies have looked into possible heat transfer enhancements (heat conductivity, heat transfer coefficient, and critical heat flux) caused by the addition of nanoparticles [9-11]. Unfortunately, all of the studies either report significant agglomeration of nanoparticles after heating or provide no indication of stability. If nanofluids are to be used for light-induced heating applications, such as volumetric solar absorption or even in medical applications [12], it is paramount that the nanoparticles remain stably suspended. When agglomeration occurs, the available surface area for radiation to be absorbed as well as the number of sites for localized heating to occur will significantly decrease. Traditionally, surfactants are used to stabilize the nanoparticles, but as the host fluid heats they tend to lose their effectiveness causing agglomeration and settling [13]. 
Additionally, solar vapor generation using nanofluids has been proposed as a method of distillation [8] and electricity generation via a steam turbine [6]. In this work, we will for the first time demonstrate that multiwalled carbon nanotubes (MWCNTs) suspended in denatured alcohol are suitable for use in a volumetric absorption solar heat pipe. MWCNTs are seen as an ideal candidate for direct solar absorption given their high spectral absorptivity over the entire solar range, ease of surface functionalization, and low cost.

\section{Materials and Methods}

MWCNTs, with an average diameter and length of approximately $31 \mathrm{~nm}$ and $4 \mu \mathrm{m}$, were grown directly from stainless steel (SS) 316 mesh using a thermal chemical vapor deposition (T-CVD) process [14]. Following the synthesis, the MWCNTs are surface-functionalized using a capacitively coupled radio-frequency glow discharge plasma sustained in an argon/oxygen/ethane gas mixture [15]. This plasma treatment has been shown to covalently graft oxygenated functionalities, such as carboxylic groups, onto the surface of the MWCNTs, thus rendering them highly dispersible in polar solvents. The detailed procedure of nanofluid production and method of UV-visible-near infrared (UV-VisNIR) characterization is provided elsewhere [16]. During the nanofluid production process, the MWCNTs are fractured as they are removed from the growth substrate by means of ultrasonication. In suspension, the average length of the MWCNTs decreases to $1.2 \mu \mathrm{m}$, while the average MWCNT diameter remains unchanged at $31 \mathrm{~nm}$ (Figure 1). Both the length and diameter distributions appear to be lognormal, which is expected given the nanofluid synthesis method [14]. Denatured alcohol (DA, Fisher Scientific: 85\% ethanol, 14\% methanol) was used as the base fluid as it is inexpensive and volatile (boiling points for ethanol and methanol are 78.4 and $64.7^{\circ} \mathrm{C}$, resp.). UV-Vis measurements were taken over the 200-1500 nm range with transmittance spectra of the pure DA taken for reference. This spectral range accounts for $85 \%$ of the total incident solar energy at air mass 1.5 and represents the limits of integration used in (2). Spectra were not taken above $1500 \mathrm{~nm}$ as strong absorption bands in the IR mask any change due to the addition of MWCNTs. However, for direct solar energy collection purposes, one can assume that the base fluid absorbs the majority of the solar irradiation above $1500 \mathrm{~nm}$. The MWCNT concentration used in the present study ranged from approximately 5 to $53 \mathrm{mg} \mathrm{L}^{-1}$.

\section{Results}

MWCNT/DA nanofluids of various concentrations, $c$ $\left[\mathrm{mg} \mathrm{L}^{-1}\right]$, were prepared and characterized. As an initial test of the long term and high temperature stability of the nanofluids, transmittance spectra of the different nanofluids were acquired over a 20-month period (Figure 2(a)) and upon cool-down after heating to $65^{\circ} \mathrm{C}$ for 1 hour (Figure 2(b)). In both cases, no agitation or sonication was applied to the nanofluids after synthesis or before the transmittance measurements. As Figures 2(a)-2(b) illustrate, the curves for essentially any given concentration overlap (less than $1.5 \%$ change in concentration), indicating that the nanofluids are extremely stable over time and at elevated temperatures. One should note that in some cases the data directly overlap making it difficult to distinguish between the dashed (after synthesis) and solid (after 20 months/heating) lines. To characterize the optical properties of the various concentrations of nanofluid, the extinction coefficient, $\alpha(\lambda, c)\left[\mathrm{cm}^{-1}\right]$ as a function of wavelength $(\lambda)$ [nm], was calculated using (1) [17]:

$$
T(\lambda)=e^{-\alpha(\lambda, c) l}
$$

As there is essentially no change in transmittance, $T(\lambda)$, over a 20 months period or after heating, the extinction coefficients shown in Figure 2(c) are representative of all of these cases. A path length $(l)$ of $1 \mathrm{~cm}$ was used for all measurements. Using the extinction coefficient, a solar spectrum-weighted stored energy fraction $\left(A_{m}\right)$ can be calculated [18]. Consider

$$
A_{m}(x, c)=\frac{\int S_{m}(\lambda)\left[1-e^{-\alpha(\lambda, c) x}\right] d \lambda}{\int S_{m}(\lambda) d \lambda} .
$$

This quantity represents the fraction of solar energy that is absorbed by the nanofluid over a particular penetration distance $(x)[\mathrm{cm}]$. The spectral distribution of the solar irradiation, $S_{m}(\lambda)\left[\mathrm{W} \mathrm{m}^{-2}\right]$, was taken at an air mass of 1.5 and the bounds of integration were set to 200 and $1500 \mathrm{~nm}$ [19]. The stored energy fractions for the various concentrations of nanofluids are presented in Figure 2(d) over a range of fluid thicknesses. It can be clearly seen that the addition of MWCNTs has a significant effect on the energy capture ability of the nanofluid and, using these results, one can easily tailor the nanofluid concentration to obtain close to $100 \%$ absorption for any particular fluid thickness.

Given that light scattering from MWCNTs has been shown to be very low [20], an optical absorption coefficient, $\alpha^{\prime}(\lambda)\left[\mathrm{L} \mathrm{mg}^{-1} \mathrm{~cm}^{-1}\right]$, which is independent of the MWCNT concentration, can be calculated using the equation commonly referred to as the Beer-Lambert law (3). Consider

$$
T(\lambda)=e^{-\alpha^{\prime}(\lambda) c l}
$$

Equation (3) predicts that if absorption is solely attributable to the MWCNTs, which is the case over the visible range (380-780 $\mathrm{nm}$ ) as DA is essentially transparent, the absorption coefficient, $\alpha^{\prime}$, should not vary as the MWCNT concentration increases. Given that the absorption coefficients were indeed found independent of the MWCNT concentration (standard deviation was less than $1 \%$ ), one can use the transmittance spectrum of a nanofluid to determine its concentration. It should be noted that deviations in the Beer-Lambert law can occur at high concentrations; however, given that the measured absorption did remain directly proportional to concentration (i.e., $\alpha^{\prime}$ remains constant), (3) is assumed to remain valid for this work.

To test if the nanofluid destabilizes when the base fluid evaporates, nanofluids of various MWCNT concentrations were left to evaporate in a fume hood at $20^{\circ} \mathrm{C}$ for 2 cycles of 24 hours each, resulting in more than $50 \%$ evaporation of the base fluid. Images of the nanofluids prior to evaporation 

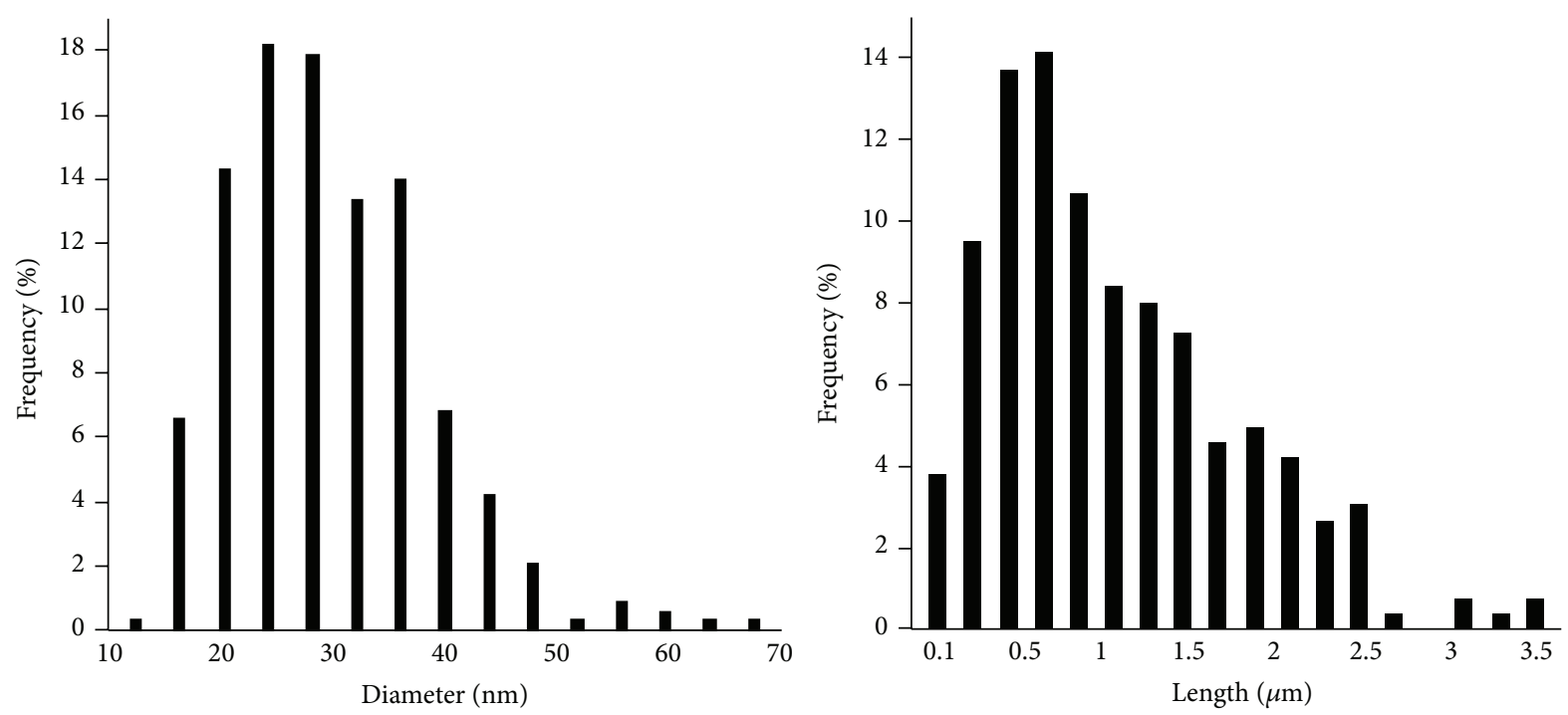

FIGURE 1: Diameter and length distributions of MWCNT fragments suspended within the nanofluid.

and after the second evaporation cycle are shown in Figure 3. The transmittance and mass of each sample were taken before and after each evaporation cycle in order to compare the MWCNT concentration of the nanofluid, determined by the mass loss of the DA, to the concentration determined through optical measurement (3). If agglomeration occurs as a result of the evaporation process, then the MWCNT concentration predicted by the transmittance measurement would be much lower than the concentration calculated from the decrease in mass. As Figure 4 shows, after two evaporation cycles, all of the concentrations determined through optical measurements (UV-Vis) are within $10 \%$ of those determined from the mass loss. The slight decrease in concentration given by the optical measurement can be attributed to the MWCNT resin that was deposited on the walls of the glass vial during the slow evaporation process (Figure 3 ). It should be noted that the MWCNT adhesion to the wall of the vial was not observed in any of the other tests and thus it can be attributed to the very slow $(\sim 2 \mathrm{~g} /$ day $)$ evaporation process that took place. The fact that the evaporation of the base fluid does not lead to agglomeration of the MWCNTs and only makes the nanofluid more concentrated, thus more absorbent, suggests that this nanofluid could be used for solar-based vapor generation applications. No optical measurement was reported for the second evaporation cycle of the most concentrated nanofluid $\left(53 \mathrm{mg} \mathrm{L}^{-1}\right)$ as the transmittance was below the detection limit for the spectrophotometer.

Given that the nanofluid has been shown to be an excellent broadband absorber, which is stable over extended periods of time and after partial evaporation of the base fluid, the final step was to determine if the nanofluid could remain stable under continuous evaporation/condensation cycling. To test this, $100 \mathrm{~mL}$ of MWCNT/DA nanofluid kept in a sealed volumetric flask was placed in a water bath at $80^{\circ} \mathrm{C}$. This temperature is above the boiling temperature of both methanol and ethanol, ensuring a significant degree of evaporation/condensation, which was clearly visible throughout the testing. A MWCNT concentration of $17 \mathrm{mgL}^{-1}$ was chosen as $100 \%$ absorption can be achieved over a fluid thickness of $5 \mathrm{~cm}$, which is a typical ETC diameter [3]. A cooling coil filled with circulating cold water surrounded the top portion of the flask to aid in the condensation process. Five evaporation/condensation cycles of 1 hour each were conducted over a five-day period with the transmission spectra of the nanofluid tested after each cycle. As Figure 5 illustrates, the curves for the MWCNT/DA nanofluid again entirely overlap and no difference in transmittance can be seen after the 5 th cycle (less than $0.2 \%$ change in concentration), indicating that no agglomeration occurs as a result of the evaporation/condensation cycling process.

\section{Discussion}

This is the first study to quantitatively demonstrate nanofluid stability upon repeated evaporation/condensation cycling. The excellent stability of the produced nanofluids can be attributed to the unique MWCNT growth and plasma functionalization processes. A relatively short exposure time ( $<5 \mathrm{~min}$ ) to the low-temperature plasma covalently bonds polar functionalities $(\mathrm{C}-\mathrm{O}, \mathrm{C}=\mathrm{O},-\mathrm{COO})$ onto the MWCNT surface [15], allowing the MWCNTs to be easily suspended in denatured alcohol (as well as other polar fluids [16]). As the purpose of this work is to show the feasibility of using a nanofluid in solar-driven latent heat applications, no further characterization of functional groups is provided here; however, a detailed study of the plasma treatment can be found elsewhere [21]. Upon suspension, deprotonation of the carboxylic groups leaves a negative surface charge on the MWCNTs, thus limiting agglomeration over time. This electrostatic repulsion is sufficient to overcome the increased number of high velocity collisions between MWCNTs that occur as the nanofluid evaporates and condenses [22]. During this process, the MWCNTs stay within the suspension and thus the vapors that are produced contain only the base fluid, 

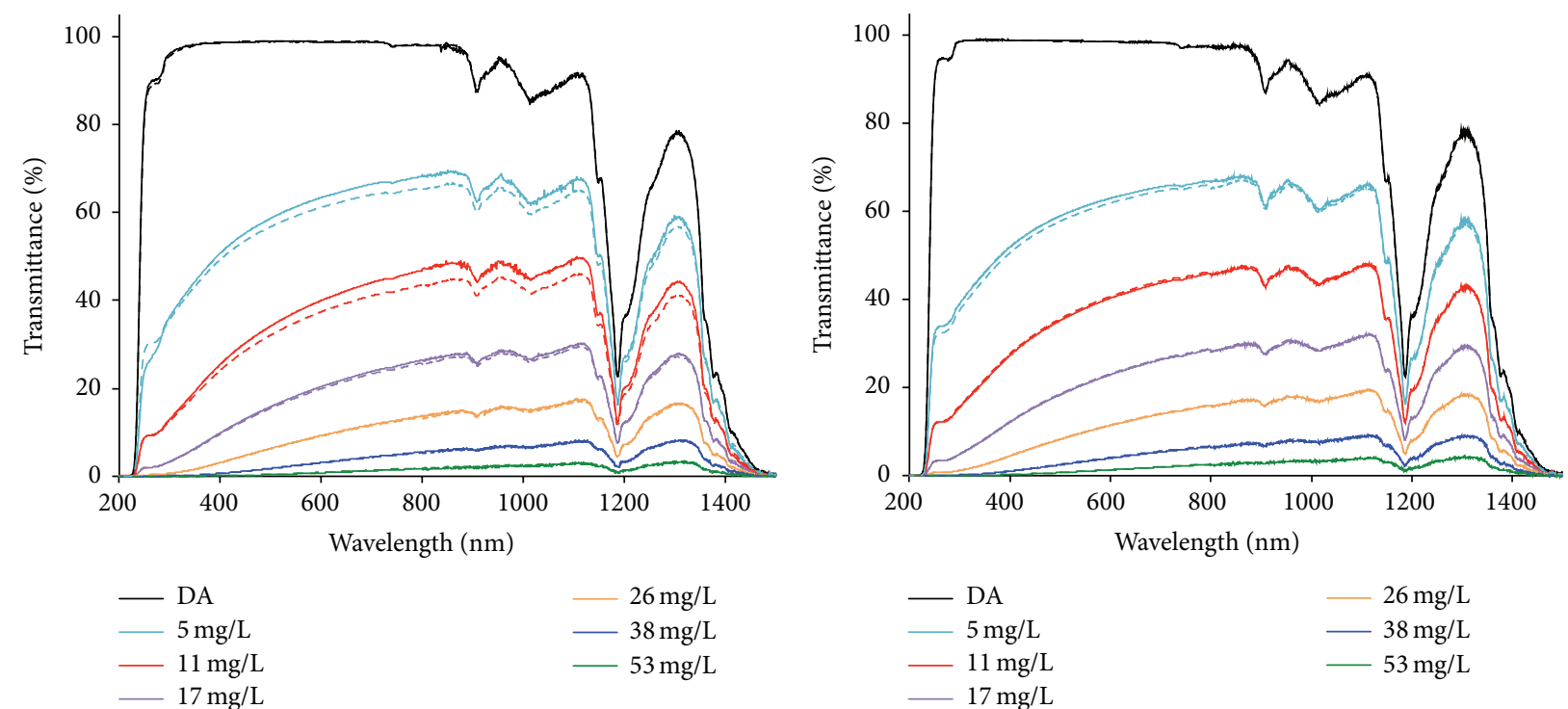

(a)
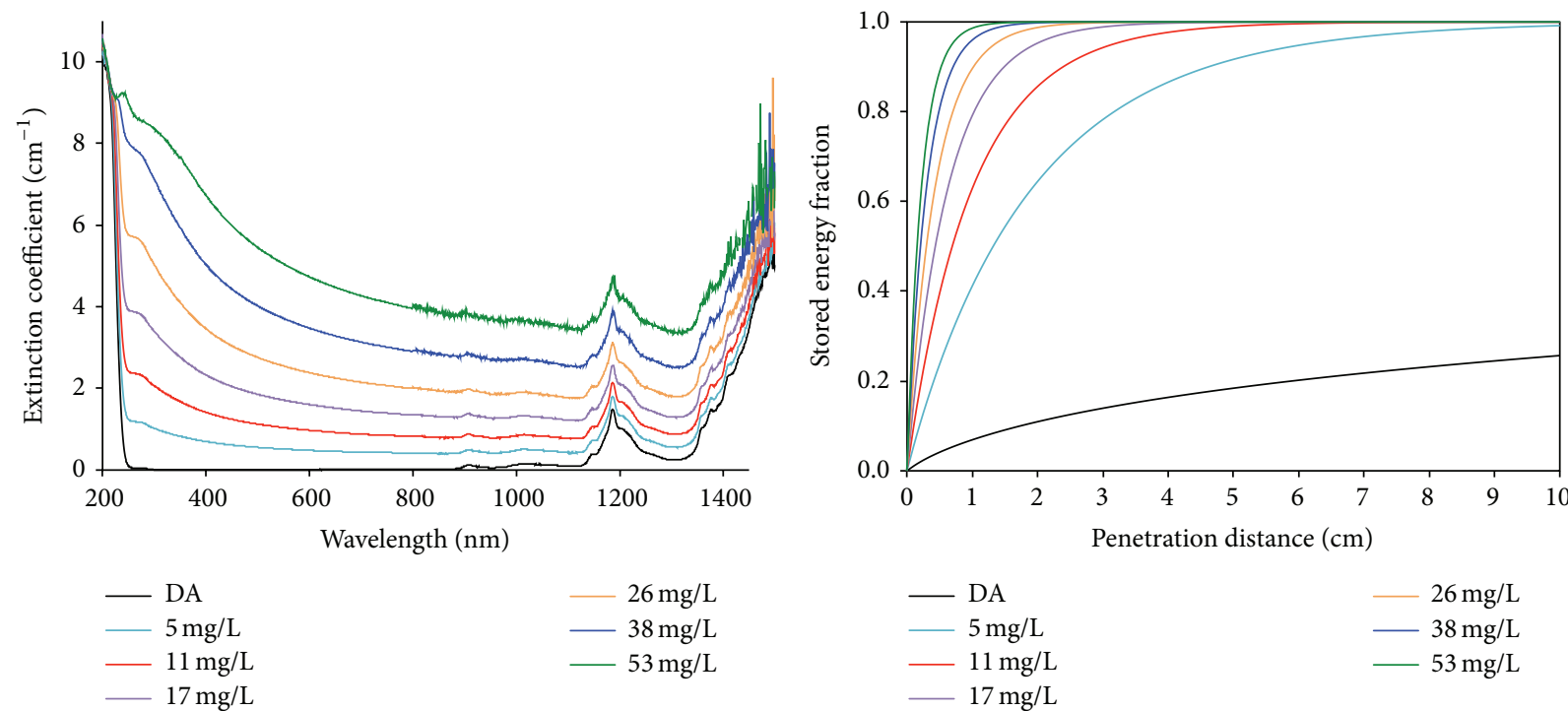

(c)

(d)

FIgURE 2: Optical characterization of various concentrations of MWCNT/DA nanofluids. (a) Transmission spectra immediately after synthesis (dash) and after 20 months (solid). (b) After synthesis (dash) and heating to $65^{\circ} \mathrm{C}$ (solid). (c) Extinction coefficients. (d) Stored energy fraction. Absorption path length was $1 \mathrm{~cm}$.

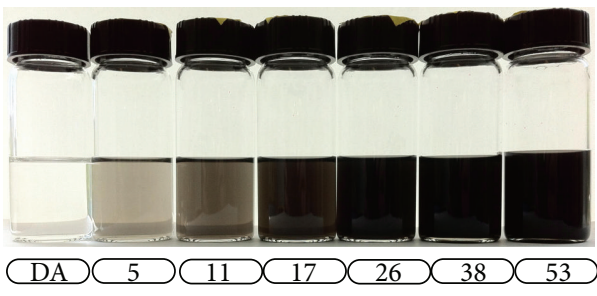

(a)

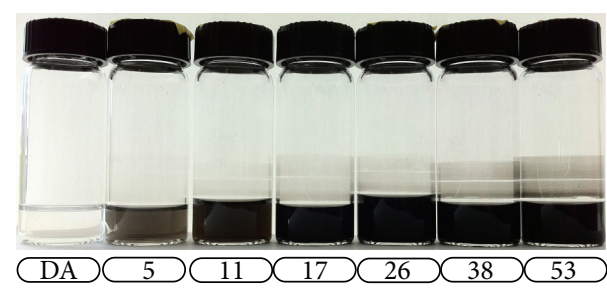

(b)

Figure 3: MWCNT/DA nanofluids after synthesis (a) and after 2 evaporation cycles (b). 


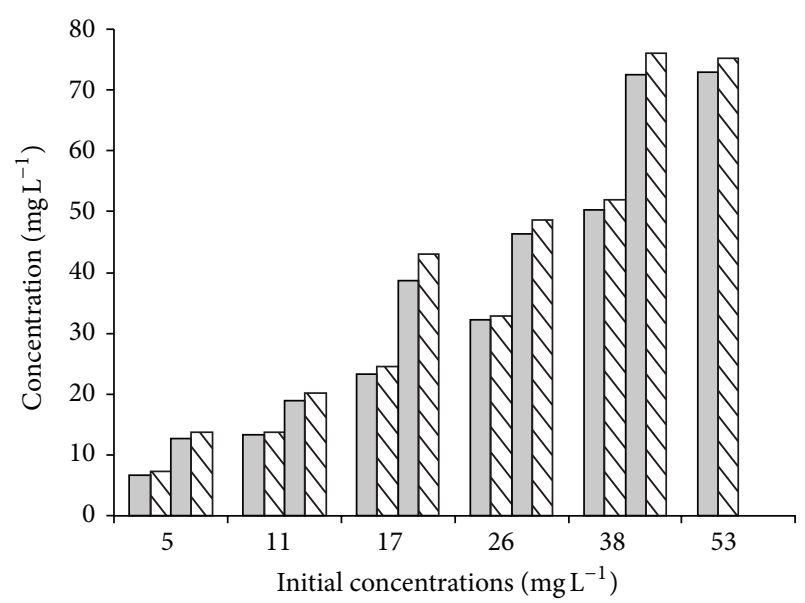

$\square$ UV-Vis

Mass

FIGURE 4: Concentration of MWCNT/DA nanofluids after 2 evaporation cycles ( 24 hours each) as determined by optical measurements (UV-Vis) and through mass difference.

which is typical of nanofluid boiling [8]. Without functionalization, the MWCNTs agglomerate immediately upon suspension and settle out (not shown). This has also been found to be the case when nonpolar base fluids are used [16]. These results, although preliminary, indicate that it is possible to use a nanofluid for a direct absorption heat pipe for latent heat-driven solar heating applications. A prototype is currently under development to characterize the optical heating/boiling efficiency using more rigorous, real-world conditions.

\section{Conclusions}

This work demonstrates the feasibility of using a nanofluid for volumetric solar energy absorption and, in particular, for conditions prevailing in a latent heat-driven heat pipe type collector. It was demonstrated quantitatively that plasmafunctionalized MWCNTs suspended in denatured alcohol do not agglomerate over extended periods of time (current testing up to 20 months) upon evaporation of the base fluid and upon repeated boiling/condensation cycles. This stability, coupled with the fact the MWCNT/DA nanofluids can absorb close to $100 \%$ of solar irradiation over a small fluid volume, suggests that these nanofluids can be used in a range of solar vapor generation applications.

\section{Conflict of Interests}

The authors declare that there is no conflict of interests regarding the publication of this paper.

\section{Acknowledgments}

The authors gratefully acknowledge the financial support provided by the Natural Sciences and Engineering Research

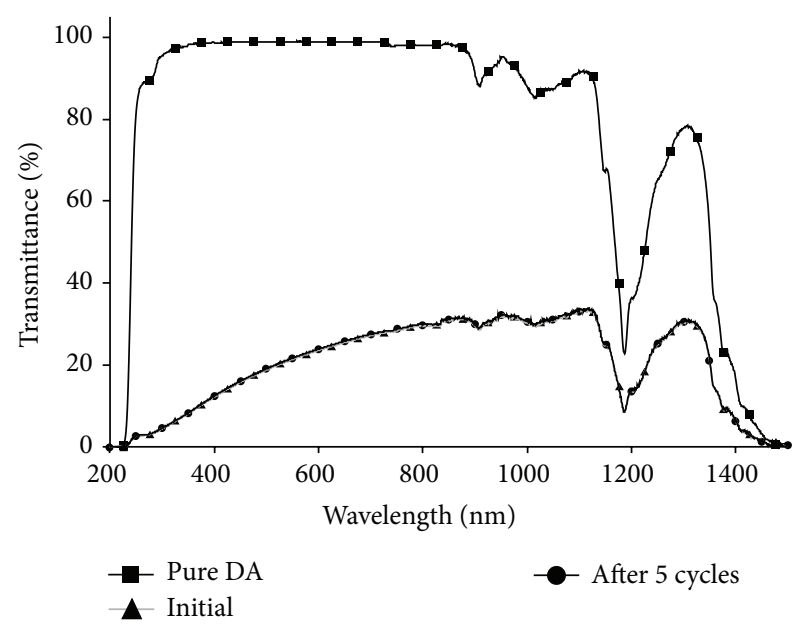

Figure 5: Transmission spectra for a $17 \mathrm{mg} \mathrm{L}^{-1}$ MWCNT/DA nanofluid before and after 5 boiling/condensation cycles. The transmission spectrum of pure DA is given as reference. Absorption path length was $1 \mathrm{~cm}$.

Council of Canada, the Fonds de recherche du QuébecNature et technologies, and McGill University.

\section{References}

[1] M. Beerepoot, Technology Roadmap Solar Heating and Cooling, International Energy Agency (IEA), Paris, France, 2012.

[2] W. Weiss and F. Mauthner, Eds., Solar Heat Worldwide, IEA, Gleisdorf, Austria, 2012.

[3] S. A. Kalogirou, "Solar thermal collectors and applications," Progress in Energy and Combustion Science, vol. 30, no. 3, pp. 231-295, 2004.

[4] T. P. Otanicar, P. E. Phelan, R. A. Taylor, and H. Tyagi, "Spatially varying extinction coefficient for direct absorption solar thermal collector optimization," Journal of Solar Energy Engineering, vol. 133, no. 2, Article ID 024501, 7 pages, 2011.

[5] L. Vasiliev, E. Hleb, A. Shnip, and D. Lapotko, "Bubble generation in micro-volumes of 'nanofluids"' International Journal of Heat and Mass Transfer, vol. 52, no. 5-6, pp. 1534-1539, 2009.

[6] R. A. Taylor, P. E. Phelan, R. J. Adrian, A. Gunawan, and T. P. Otanicar, "Characterization of light-induced, volumetric steam generation in nanofluids," International Journal of Thermal Sciences, vol. 56, pp. 1-11, 2012.

[7] R. A. Taylor, P. E. Phelan, T. Otanicar, R. J. Adrian, and R. S. Prasher, "Vapor generation in a nanoparticle liquid suspension using a focused, continuous laser," Applied Physics Letters, vol. 95, no. 16, Article ID 161907, 2009.

[8] O. Neumann, A. S. Urban, J. Day, S. Lal, P. Nordlander, and N. J. Halas, "Solar vapor generation enabled by nanoparticles," ACS Nano, vol. 7, no. 1, pp. 42-49, 2013.

[9] J. Barber, D. Brutin, and L. Tadrist, "A review on boiling heat transfer enhancement with nanofluids," Nanoscale Research Letters, vol. 6, no. 1, p. 280, 2011.

[10] Z.-H. Liu, X.-F. Yang, G.-S. Wang, and G.-L. Guo, "Influence of carbon nanotube suspension on the thermal performance of a miniature thermosyphon," International Journal of Heat and Mass Transfer, vol. 53, no. 9-10, pp. 1914-1920, 2010. 
[11] L. Lu, Z.-H. Liu, and H.-S. Xiao, “Thermal performance of an open thermosyphon using nanofluids for high-temperature evacuated tubular solar collectors. Part 1: indoor experiment," Solar Energy, vol. 85, no. 2, pp. 379-387, 2011.

[12] H. K. Moon, S. H. Lee, and H. C. Choi, "In vivo near-infrared mediated tumor destruction by photothermal effect of carbon nanotubes," ACS Nano, vol. 3, no. 11, pp. 3707-3713, 2009.

[13] A. Ghadimi, R. Saidur, and H. S. C. Metselaar, "A review of nanofluid stability properties and characterization in stationary conditions," International Journal of Heat and Mass Transfer, vol. 54, no. 17-18, pp. 4051-4068, 2011.

[14] N. Hordy, N.-Y. Mendoza-Gonzalez, S. Coulombe, and J.-L. Meunier, "The effect of carbon input on the morphology and attachment of carbon nanotubes grown directly from stainless steel," Carbon, vol. 63, pp. 348-357, 2013.

[15] N. Hordy, S. Coulombe, and J.-L. Meunier, "Plasma functionalization of carbon nanotubes for the synthesis of stable aqueous nanofluids and poly(vinyl alcohol) nanocomposites," Plasma Processes and Polymers, vol. 10, no. 2, pp. 110-118, 2013.

[16] N. Hordy, D. Rabilloud, J.-L. Meunier, and S. Coulombe, "High temperature and long-term stability of carbon nanotube nanofluids for direct absorption solar thermal collectors," Solar Energy, vol. 105, pp. 82-90, 2014.

[17] F. H. Perrin, "Whose absorption law?" Journal of the Optical Society of America, vol. 38, no. 1, pp. 72-74, 1948.

[18] W. D. Drotning, "Optical properties of solar-absorbing oxide particles suspended in a molten salt heat transfer fluid," Solar Energy, vol. 20, no. 4, pp. 313-319, 1978.

[19] ASTM International, ASTM G173-03, Standard Tables for Reference Solar Spectral Irradiances: Direct Normal and Hemispherical on $37^{\circ}$ Tilted Surface, ASTM International, West Conshohocken, Pa, USA, 2012.

[20] Y. Gan and L. Qiao, “Optical properties and radiation-enhanced evaporation of nanofluid fuels containing carbon-based nanostructures," Energy and Fuels, vol. 26, no. 7, pp. 4224-4230, 2012.

[21] N. Hordy, J.-L. Meunier, and S. Coulombe, “Thermal stability of plasma generated oxygenated functionalities on carbon nanotubes," Plasma Processes and Polymers, vol. 12, no. 6, pp. 533-544, 2015.

[22] A. Amrollahi, A. A. Hamidi, and A. M. Rashidi, "The effects of temperature, volume fraction and vibration time on the thermo-physical properties of a carbon nanotube suspension (carbon nanofluid)," Nanotechnology, vol. 19, no. 31, Article ID 315701, 2008. 

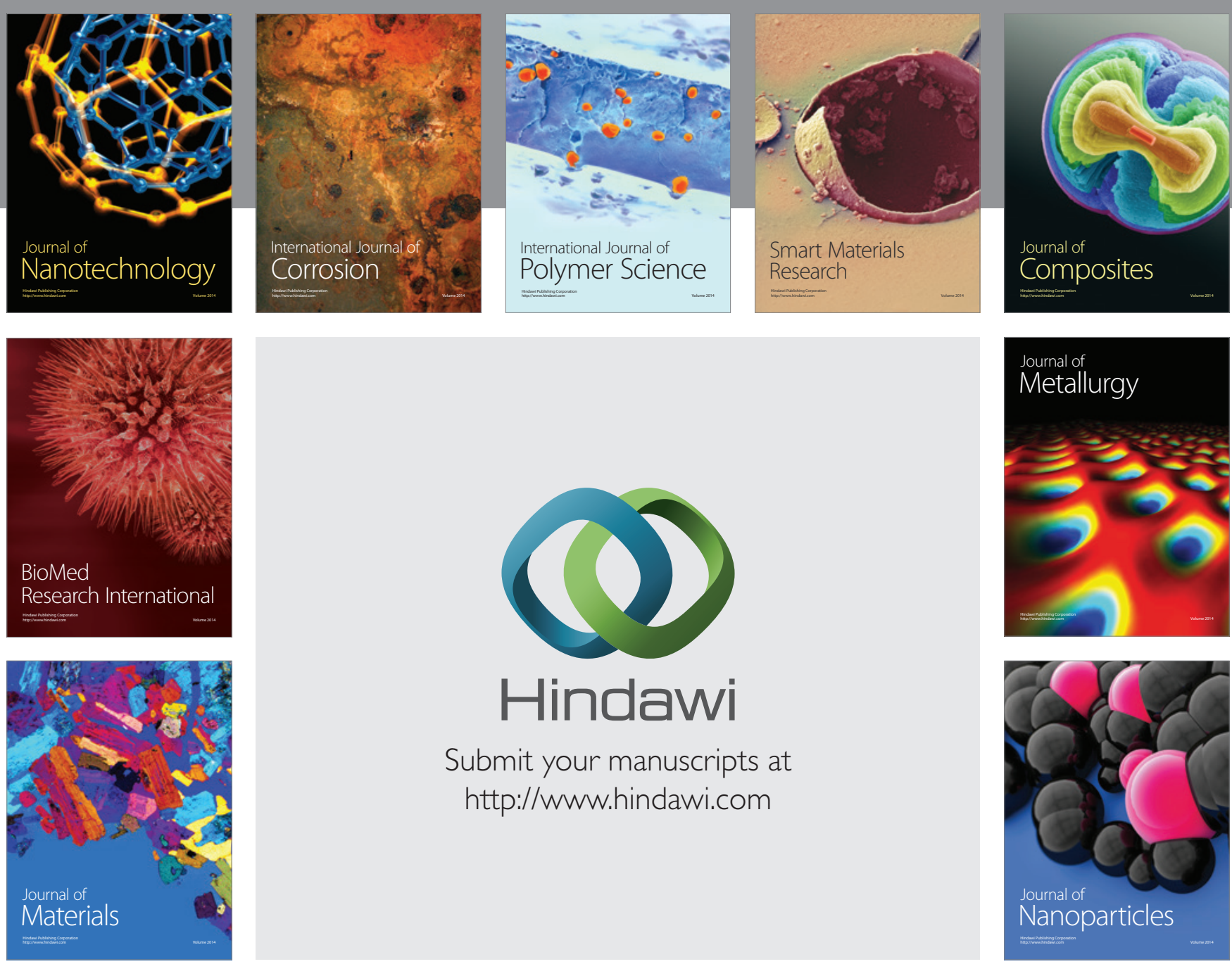

Submit your manuscripts at http://www.hindawi.com
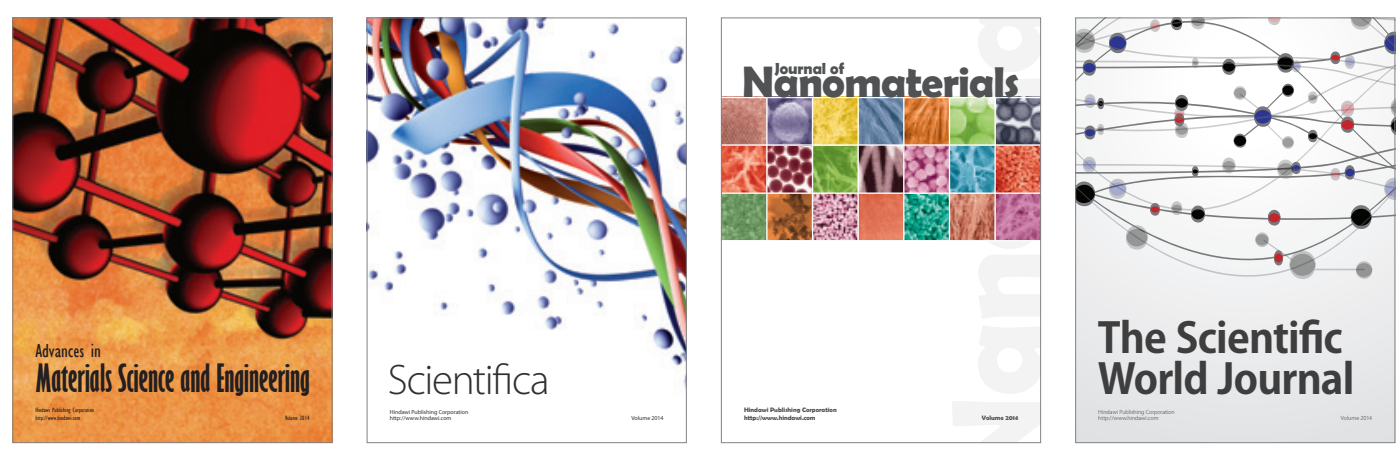

\section{The Scientific World Journal}
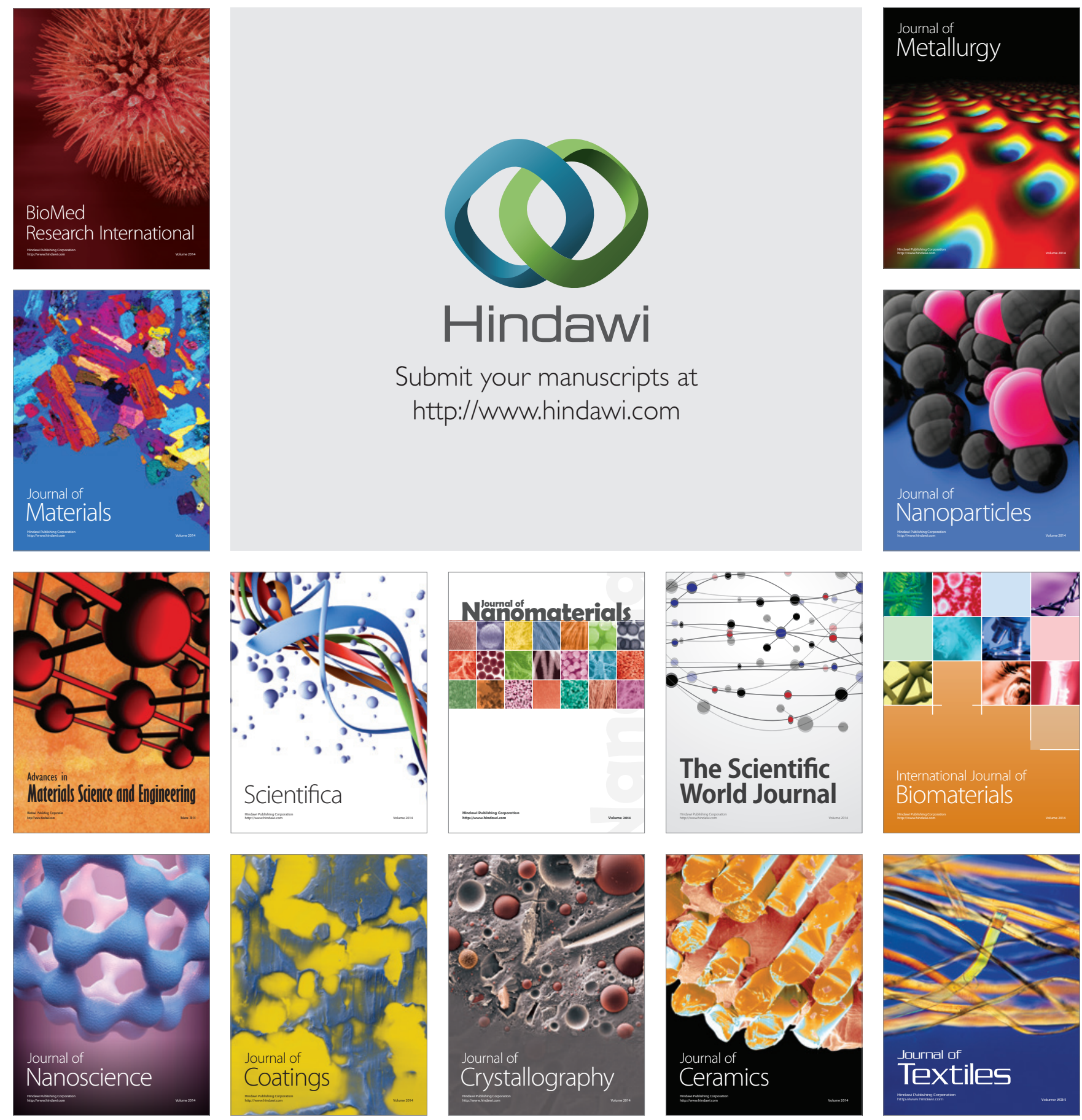